\title{
Die Aufnahme von Eisen durch die menschliche Placenta aus dem maternen Blute.
}

\author{
Erste Mitteilung. \\ Von
}

J. Hof bauer, Wien.

(Der Redaktion zugegangen am 5. November 1903.)

Die Erkenntnis, daß der menschlichen Placenta die Fähigkeit innewohnt, aus der Umgebung Fette aufzunehmen und dem fötalen Organismus zuzuführen, war vornehmlich auf den mikrochemischen Nachweis innerhalb der Chorionzotte zurückzuführen. In einer vorläufigen Mitteilung (Verf., Diese Zeitschrift, Bd. XXXIX, H. 5) und einer ausführlichen Publikation (Sitzung der K. Akademie d. Wissensch., 15. Okt. 1903) wurde darüber berichtet, daß es bei Behandlung frisch gewonnener Placenten in Flemmingscher und Hermannscher Lösung gelünge, durch die Osmierung der Fettkörnchen die Wege kennen zu lernen, die der Resorptionsstrom, also hier gekennzeichnet durch das Fett, innerhalb der Zotte nimmt. Wir sahen das F'ett den Stäbchensaum des Syncytiums passieren (hier wohl nur ausnahmsweise kenntlich), dann ins Syncytium übertretend daselbst insbesondere in der Kern- und Unterkernzone eine dichte Infiltration desselben in feiner staubartiger Verteilung oder wieder als gröbere Körner darstellen, fernerhin durch die Langhansschicht, den subepithelialen Raum und die membrana limitans ins eigentliche Zottenstroma gelangen und auf, resp. in den Bindegewebszügen zu Knotenpunkten wandern, die durch zellige Gebilde gekennzeichnet sind. Dann tritt das Fett auf schmalen Bahnen in die Hüllmembran der Lymphspalten und die denselben angehörigen großen, ästigen, vacuolären Zellen (s.' Verf., «Über das konstante Vorkommen etc », Wiener klin. 
Wochenschr., Juli 1903), ist schließlich im Plasma der zelligen Elemente nachweisbar, welche der Wandung der fötalen Blutkapillaren eigen sind, und weiterhin gelegentlich im Lumen der Gefäße selbst. Damit war fürs erste eine auffallende Ähnlichkeit mit dem Vorgange der Fettresorption in der Dünndarmzotte gegeben, eine Ähnlichkeit, die noch dadurch erhöht wird, daß der Stäbchensaum des Syncytiums fast vollständige Übereinstimmung mit dem des Darmepithels zeigt, und fernerhin das elektive Vermögen der Placentarzotte, Nährstoffe aus dem umgebenden Blute aufzunehmen, festgestellt.

Diese Ergebnisse legten nun den Gedanken nahe, auch bezüglich des Eisens zu ermitteln, ob dieser wichtige Blutbestandteil aus der maternen Zirkulation durch Vermittlung der Placenta in den fötalen Kreislauf hinübergeleitet würde. Dies erschien um so aussichtsvoller, als der lang geführte Streit betreffs einer Eisenaufnahme im menschlichen Darm gerade durch mikrochemische Methoden dahin entschieden wurde, daß dem Duodenum in der Tat, und zwar so gut wie ausschließlich, diese Fähigkeit zukommt (Quincke und Hochhaus, Hall, Gaule) und auch fernerhin von besonderer Wichtigkeit deshalb, weil verschiedene Momente mit zwingender Notwendigkeit darauf hinwiesen, daß bei der Entwicklung des Säugetiereies Eisen aus dem mütterlichen Organismus her aufgenommen werden müsse, um die Bildung der Blutscheiben zu ermöglichen. Bonnet und seine Schule hatten diesbezüglich des öfteren auf den Unterschied zwischen dem mit Eisen reichlich versehenen Dotter des Vogel- und Reptilienkeimes und dem holoblastischen Ei der Säuger hingewiesen (Kolster in Anat. Hefte, Bd. LIX, LXIV und LXVIII). Tatsächlich konnte auch an den Fruchtblasen der Säuger die Aufnahme von teils erhaltenen, teils zerfallenen roten Blutzellen und von Hämatoidinkrystallen durch das Chorionektoderm nachgewiesen werden. Kolster (l. c.) zeigte dies für die Placentation der Maus und der Wiederkäuer, Strahl führte diesen Nachweis an der diffusen Halbplacenta der Eselin, Lieberkühn, Heinricius, Strahl und Bonnet an der gürtelförmigen Placenta der Raubtiere (nach Hartwig, Handbuch d. Entwicklungsgesch. 1902), Bonnet wies als Quelle für diese 
Eisenaufnahme auf die periodischen Blutungen während der Gravidität hin, gewissermaßen als Fortsetzung der Brunstblutungen, von kleinen Ecchymosen bei Hufern angefangen bis hinauf zu den großen embryotrophischen Placentarhämatomen der Raubtiere (Deutsche med. Wochenschr. 1899, Nr. 45).

Betreffs der menschlichen Placenta finden sich zunächst nach Bonnet in dem die Zotten umspülenden mütterlichen Blute bei frisch fixierten Fruchtblasenstücken «neben vollkommen und tadellos erhaltenen roten Blutkörpern auch alle Stadien der Rückbildung, Verklumpung und Auflösung, die schon intra vitam vorhanden waren, genau so, wie man sie auch in der tierischen Placenta antrifft; und es läßt sich weiterhin durch elektive Färbung mit Eosin und Rubin nachweisen, daß gelöstes, aus den Blutergüssen in der Umgebung der Zottenenden stammendes Hämoglobin auch von der Deckschicht menschlicher Fruchtblasen in ausgiebiger Weise aufgenommen wird» (in Monatsschr. f. Geburtsh., Juliheft 1903).

Daß in Wirklichkeit Eisen reichlich auf den Fötus übergeleitet werde, beweisen die Zahlen, die bei der bezüglichen Verarbeitung von fötalen Organen gewonnen wurden. So kommt Krüger (Über den Eisengehalt etc., in Zeitschr. f. Biologie, Bd. 27) zu dem Ergebnis, der Eisengehalt der Leberzellen von Föten sei im Durchschnitt zehnmal größer als der erwachsener Tiere, dabei in den verschiedenen fötalen Entwicklungsstadien ein verschiedener. Es bekommt also der Säugling bei der Geburt einen großen Eisenvorrat in seinen Geweben aufgespeichert mit, und Bunge, der auf den befremdend geringen Eisengehalt der Milch hinweist, sieht eben in dieser fötalen Eisenanhäufung eine teleologische Einrichtung, mit der Bestimmung, erst dann erschöpft zu sein, sobald der Säugling von der eisenfreien oder eisenarmen Milchnahrung zur eisenreicheren Nahrung übergeht, eine Annahme, die durch eine größere Zahlenreihe gestützt wird (Über die Aufnahme des Eisens in den Organism. des Säugl., Diese Zeitschr., Bd, XVI u. XVII).

Zur orientierenden Analyse der Vorgänge bei der Eisenresorption durch die menschliche Placenta wandte nun ich bei meinen Untersuchungen, ebenso wie für den Nachweis der 
Fette, die mikrochemische Versuchsmethode an. $\mathrm{Zu}$ diesem Zwecke stehen für die Auffindung des Eisens in Schnitten zwei Verfahren zur Verwendung, die Schwefelammonium- und die Berlinerblaureaktion. Die Schwefelammoniumreaktion beruht auf der Bildung von grünschwarzem, wasserhaltigem Ferrosulfit mit Ferroionen. Da dieses an der Luft bald zu FeSO 4 oxydiert wird und letzteres mikrochemisch farblos ist, so können die Schnitte nicht nachgefärbt werden und eignen sich auch nicht zur Konservierung.

Die zweite Reaktion mit Ferrocyankalium und Salzsäure basiert auf der Bildung der kolloiden Berlinerblauverbindung. Die Reaktion ist ungemein empfindlich; die Grenze der Empfindlichkeit ist bei $0,07 \mu \mathrm{g}$ Fe. Zur Nachfärbung eignet sich am besten eisenfreier Alaunkarmin. Um bei der Härtung der Präparate das Übertreten von Eisen in den Alkohol tunlichst zu vermeiden, hat Hall den Kunstgriff angewendet, schon bei der Härtung das im Gewebe enthaltene Eisen in unlösliches Schwefeleisen umzuwandeln (Du Bois Reymonds Archiv 1896). Der Gang der Untersuchung gestaltete sich demgemäß hier folgendermaßen. Stückchen von frisch erhaltenen Placenten (zumeist aus den früheren Schwangerschaftsmonaten) wurden sofort nach ihrer Gewinnung mit 1\%iger Kochsalzlösung abgespült und hierauf in die Hallsche Lösung gebracht (5,0\% Schwefelammonlösung, 25,0\% Aq., 70,0\% absoluter Alkohol), darin 24 Stunden aufbewahrt; sodann aufsteigende Alkoholhärtung durch 70-95\% \%, schließlich absoluten Alkohol, Präparation zur Celloidineinbettung, oder besser Einschluß in Paraffin. Anfertigung von $3 \mu$-Schnitten, die mit Wasser auf dem Objektträger fixiert werden, Befreiung der Schnitte vom Paraffin und Behandlung derselben zum zweitenmale mit der Schwefelammonlösung oder behufs Erzielung der Berlinerblaureaktion Überführung der Schnitte in eine Lösung von 1,5\% Ferrocyankali und 0,5\% Salzsäure durch 25 Minuten, Abspülen in Wasser, kurze Nachfärbung in Alaunkarmin, Alkohol, Xylol, Balsam. Als wohl selbstverständlich sei nebenher erwähnt, daß bei der Manipulation mit den Schnitten nur Platinnadeln und Glasspatel verwendet werden dürfen. In diesem Sinne behandelte Schnitte zeigen die Eisenreaktion im Gewebe der Chorionzotte in einer alle Zweifel ausschließenden Deutlichkeit. 
Es hieße nun im großen und ganzen den für die Resorption der Fette geschilderten Weg nochmals skizzieren, sollen wir die Stellen anführen, an denen das durch die Färbung markierte Eisen sichtbar hervortritt. Die obere Zone des Syncytiums freilassend, liegen die zarten, schwarzbraunen Körnchen dicht aneinander gehäuft mehr gegen dessen Basalteil und folgen dann den Bindegewebezügen, die von der Zottenperipherie gegen das Zentrum führen. Die Beziehungen zu den Gewebeelementen der Chorionzotte werden aber bei Nachfärbungen, die eben nur die Berlinerblaureaktion gestattet, deutlicher. Hier sehen wir dichte und zarte, flache blaue Netze an der Grenze von Zottenmantel und Zottenstroma. Bei stärkeren Vergrößerungen setzen sich diese Netze zusammen aus einer Aneinanderreihung und Häufung von feineren und gröberen blauen Körnchen und Schollen. Vom Zottenepithel her ziehen blaue Körnchen zu diesen Netzen herab und ebenso sind solche in den Bindegewebslamellen des stratum proprium nachweisbar, nur mit dem Unterschiede, daß in dem Grade, als wir uns dem Zentrum der Zotte nähern, die blauen Pünktchen immer zarter und feiner werden, schließlich nur bei aufmerksamster Beobachtung und Verwendung von Immersionssystemen $z u$ finden sind. Daneben sieht man stellenweise, aber im großen und ganzen selten, eine diffuse blaue Färbung einzelner peripherer Zonen des Zottengewebes.

Die Ähnlichkeit dieser Bilder, mit denen verglichen, welche wir bei der Fettresorption der Chorinzotte sahen, ist somit eine auffallende. Allerdings sind für histologische Details die Präparate der letzteren weit vorteilhafter, da die hierfür verwendete Flemmingsche Lösung ein ausgezeichnetes Konservierungsmittel der Gewebe darstellt, während das für die Eisenreaktion verwendete Schwefelammonium wohl das Zottenepithel gut erhält, die Bindegewebselemente aber stark zur Quellung bringt und dadurch die Strukturbilder undeutlicher werden. Es kommt aber schließlich für den hier zu führenden Nachweis weniger auf histologische Einzelheiten an, als vielmehr auf die einwandfreie, unzweideutige Beweisführung, daß eben die Eisenreaktion positiv ausfällt und an gut angefertigten Präparaten die reichliche Aufnahme von Eisen unverkennbar ist. Die 
Resorptionswege in der Chorionzotte dürften für Fette und für das Eisen nach den bisherigen Untersuchungen im allgemeinen die gleichen sein. Im übrigen verweisen. wir diesbezüglich schon hier auf die vitalen Placentarfärbungen, die wesentliche Aufschlüsse auch hier in Fragen der Resorption liefern, über welche aber an anderer Stelle referiert werden soll.

Was ist nun mit dem positiven Ausfall der Eisenreaktion im Zottengewebe bewiesen?

Zur Beantwortung dieser Frage sei es gestattet, wieder auf die früher zitierte, unter Gaules Leitung durchgeführte Arbeit von Hall zurückzugreifen. Danach müssen wir bei der Eisenaufnahme im allgemeinen unterscheiden "zwischen Eisen, welches in diejenigen Verbindungen aufgenommen wird, welche an dem Stoffwechsel aktiv teilnehmen, wie z. B. im Hämoglobin und in den Eisenverbindungen des Protoplasmas, und demjenigen Eisen, welches zwar ein Bestandteil des Organismus ist, aber noch nicht ein Bestandteil seiner aktiv tätigen Elemente».

Das erstere Eisen ist in sehr fester Form gebunden und kann nur durch die Analyse, aber durch keine mikrochemische Reaktion nachgewiesen werden. Hingegen kann das locker gebundene Eisen durch chemische Agentien im mikroskopischen Bilde kenntlich gemacht werden, und eine wichtige Eigenschaft desselben ist es, daß es eben abgespalten werden kann, ohne daß die Gewebe, in denen es sich befindet, zerstört werden.

Der Chorionzotte muß somit die Fähigkeit innewohnen, aus ihrer Umgebung Eisen aus bestimmten Verbindungen abzuspalten und in sich aufunehmen. Ein Eisenalbuminat durchdringt im gelösten Zustand den Syncytialsaum, wird aber bald feinkörnig niedergeschlagen. Dabei werden die Eisenpartikelchen, je mehr wir uns den zentral gelegenen Safträumen nähern, immer zarter und winziger und entziehen sich schließlich im mikroskopischen Bilde der Beobachtung, müssen somit offenbar wieder in feste organische Bindungen übergeführt worden sein.

Die Beantwortung der Frage, woher dieses in der Placenta nachweisbare Eisen gewonnen werden mag, wird wohl von vornherein keinen Schwierigkeiten begegnen. Nur nebenher 
gestreift seien hier die Erfahrungen aus jüngster Zeit, gemäß denen auch für die menschliche Placentation ein Zerfall von mütterlichem Schleimhautgewebe statthat und die Bestandteile derselben, also auch Zerfallsprodukte mütterlichen Blutes beim Aufbau des Embryonalleibs Verwendung finden (Bonnet, Hofbauer). Für die spätere Entwickelung müssen wir wohl in dem die Zotten umspülenden mütterlichen Blute die Quelle erblicken, aus der die Nahrungsstoffe für den Fötus aufgenommen werden. Nun ist nach der Auffindung der Fettresorption die übliche Lehre von der Osmose für den Übertritt von Stoffen von Mutter auf Kind sehr ins Wanken geraten und wenigstens für die Aufnahme der Fette eine aktive Betätigung von seiten des Zottenepithels sogut wie sichergestellt. Bezüglich der Verarbeitung der roten Blutzellen, als Träger der Eisenverbindungen des Blutes, ist nun nach den Erfahrungen über die Eisenaufnahme durch die placentare Zotte eine gleiche Annahme wohl unabweislich.

Vorher schon hatten Scholten und Veit (in Zeitschr. f. Geburtsh., Bd. 49) bei Untersuchungen über Syncytiolyse und Hämolyse eine gegenseitige Einwirkung von Erythrocyten und Chorionektoderm aufeinander darzulegen versucht. «Die Chorionepithelien bilden einen Antikörper gegen Erythrocyten, die Erythrocyten werden durch Seitenketten an die Chorionepithelien gebunden». Das von den Zottenepithelien gebildete Hämolysin vermag Erythrocyten aufzulösen, das Hämoglobin kann darum im Serum gelöst vorkommen, verschwindet aber sofort wieder aus demselben. Nur wenn es in außergewöhnlicher Menge gelöst wurde, bleibt es im Serum nachweisbar, dann findet man Hämoglobinämie; ist es in noch größerer Menge vorhanden, so wird es zur Hämoglobinurie kommen. Das Chorionektoderm bildet also auch beim Menschen ein Cytotoxin, unter dessen Einfluß Erythrocyten zerfallen und Eisen ins Serum übertritt, und dieses Hämolysin ermöglicht erst die Aufnahme der Bestandteile des roten Blutkörperchens, ein Vorgang, der dem analog, wonach das parietale Blatt des Dotterentoderms bei der tierischen Placentation Hämoglobin aufzunehmen imstande ist. 
Gestützt und erweitert wurde diese Lehre von Wychgel (Zeitschr. f. Geb., Bd. 47). Derselbe fand vermehrten Eisengehalt im Harne der Graviden, ferner 8 mal Hämoglobinämie unter 23 Schwangeren. Nach diesem Autor bildet sich bei normaler Gravidität neben dem Hämolysin auch ein Antihämolysin, und nur in pathologischen Fällen, wo sich kein Antikörper bei der Entstehung des Autohämolysins bildet, kommt es zu schwerer progressiver Anämie oder Morbus maculosus oder zu habituellem Icterus in der Gravidität mit Hämoglobin im Harn, Beobachtungen, wie sie von Gusserow, Diehl und Becking in der Literatur niedergelegt sind. Auch die Eclampsie gehöre hierher: "Hier treten die toxischen Wirkungen gegenüber den lytischen in den Vordergrund».

Kehren wir von diesem Ausblick auf das pathologische Gebiet wieder zur Physiologie der Schwangerschaft zurück, so haben wir in dem mikrochemischen Nachweis des Eisens in der unter einwandfreien Bedingungen konservierten Chorionzotte einen neuen Anhaltspunkt für das Bestehen dieses hämolytischen Prozesses und auch annähernd für die Menge des aufgenommenen Eisens gewonnen. Die Frage, wie die fötalen Organe, denen das Eisen reichlich in geschilderter Weise zugeführt wird, vor allem die fötale Leber, dasselbe zur Hämoglobinbildung verwerten, soll hier nicht weiter erörtert werden. Nach Kunkel (Blutbildung aus anorgan. Eisen in Pflügers Archiv, Bd. 61) hat die Leber normalerweise «neben anderen Funktionen auch die, als Behälter für den Eisenvorrat zu dienen; der hohe Eisengehalt und die bedeutende absolute Größe der Leber bei neugeborenen Säugetieren spricht dafür».

Nachtrag bei der Korrektur: Bei Gelegenheit der Besprechung meiner Untersuchungsresultate werde ich durch das gütige Entgegenkommen von Herrn Prof. Kretz auf eine einschlägige Arbeit von Tirmann und Lipski aufmerksam gemacht («Über den Übergang des Eisens zum Kinde»). Dieselbe, in den im allgemeinen weniger zugänglichen «Görbersdorfer Veröffentlichungen von Kobert» (1898) erschienen, findet sich 
248 J. Hofbauer, Aufnahme v. Eisen durch die menschl. Placenta etc.

sonst nicht zitiert. Die Autoren untersuchten schwangere Uteri von Tieren, ebenso Eihäute und Placenten mit Hilfe der Eisenreaktion, und fanden vom Uterus ausgehend Lymphgefäße in die Placenta ziehen, welche reichliche Mengen eisenenthaltender lymphoider Zellen beherbergen, und lassen es unentschieden, «ob die eisenbeladenen Leukocyten aus dem mütterlichen Kreislauf in den kindlichen übergehen, oder ob nur ein Aneinanderlagern der eisenbeladenen mütterlichen und der eisenhungrigen kindlichen Leukocyten an der Grenzscheide zwischen mütterlichem und kindlichem Kreislauf stattfindet, wobei das Eisen von den beladenen auf die leeren Leukocyten übergeht». In den Chorionzotten einer menschlichen Placenta fand Tirmann die Hauptmenge des Eisens an der Peripherie der Zotte. «Hiernach dürfte dem mütterlichen Organismus die Fähigkeit zugesprochen werden, Eisen frei zu machen, d. h. aus komplizierter fester Bindung Eisen in lockere Verbindung überzuführen. Die eisenhaltige Placentarmilch dürfte als Beweis gelten». 